\title{
KEPUTUSAN KONSUMEN TERHADAP PEMBELIAN TANAMAN HIAS SELAMA PANDEMI DI KECAMATAN KOTABUMI SELATAN
}

\author{
INFLUENCING CONSUMERS TO PURCHASE ORNAMENTAL PLANTS DURING \\ PANDEMIC IN KOTABUMI SELATAN DISTRICT
}

\begin{abstract}
Yuni Elmita Sari , Feby Musti Ariska dan Sri Puji Lestari
Dosen Program Studi Agribisnis, Fakultas Pertanian dan Peternakan, Universitas Muhammadiyah Kotabumi, Lampung Utara, Lampung Email: yuni.elmitasari@umko.ac.id
\end{abstract}

\begin{abstract}
The purposes of this study were 1.) To find out the types of ornamental plants purchased by consumers in Kotabumi Selatan District. 2.) Knowing what factors influence consumer decisions to buy ornamental plants in Kotabumi Selatan District. The method in this research is a survey method. This research was conducted in Kotabumi Selatan Subdistrict, North Lampung Regency because it is one of the regencies in Lampung Province that has a fairly high impact of Covid19. The location of the research was done intentionally. Accidental sampling method (accidental sample) is used to determine the sample on consumers who buy ornamental plants. Based on the research results, the types of sri fortune (aglaonema), widow bolong (Monstera adansonii), chrysanthemum, and various taro. based on the order of the most fans is Sri Rejeki (Aglaonema). Factors that influence consumers to buy ornamental plants are cultural factors (X1) of 20.02 percent, social factors (X2) of 20.22 percent, personal factors of (X3) 35.41 percent, and psychological factors of 24.35 percent so that the personal factor (X3) of 35.41 percent is the biggest factor influencing consumers to buy ornamental plants.
\end{abstract}

Keywords: Consumers,Factors Pandemic,Purcase,Ornamental plants.

\begin{abstract}
Abstrak :. Tujuan penelitian ini adalah 1.) Mengetahui jenis tanaman hias yang dibeli oleh konsumen di Kecamatan Kotabumi Selatan. 2.) Mengetahui faktor apa saja yang mempengaruhi keputusan konsumen untuk membeli tanaman hias di Kecamatan Kotabumi Selatan. Metode dalam penelitian ini adalah metode survey. Penelitian ini dilakukan di Kecamatan Kotabumi Selatan Kabupaten Lampung Utara dikarenakan menjadi salah satu kabupaten di Provinsi Lampung yang berdampak Covid-19 cukup tinggi. Lokasi penelitian dilakukan secara sengaja. Metode accidental sampling (sampel kebetulan) digunakan untuk meenentukan sampel pada konsumen yang membeli tanaman hias. Berdasarkan hasil penelitian jenis sri rejeki (aglaonema), janda bolong (Monstera adansonii),krisan, dan bermacam keladi. berdasarkan urutan peminat terbanyak adalah sri rejeki (aglaonema). Faktor yang mempengaruhi konsumen untuk membeli tanaman hias yakni yakni faktor budaya $\left(X_{1}\right)$ sebesar 20,02 persen, faktor sosial $\left(X_{2}\right)$ sebesar 20,22
\end{abstract}


persen, faktor pribadi sebesar $\left(\mathrm{X}_{3}\right)$ 35,41 persen, dan faktor psikologis sebesar 24,35 persen sehingga faktor pribadi $\left(\mathrm{X}_{3}\right)$ sebesar 35,41 persen merupakan faktor terbesar yang mempengaruhi konsumen untuk melakukan pembelian tanaman hias.

Kata Kunci: Faktor, Konsumen, Pandemi, Pembelian, Tanaman Hias.

\section{PENDAHULUAN}

Agribisnis tanaman hias di Indonesia saat ini cukup menjanjikan. Selain berperan dalam mengembangkan sektor petanian juga berperan dalam pertumbuhan ekonomi dan perkembangan agrowisata. Tanaman hias merupakan jenis tanaman kebutuhan sekunder. Walaupun tergolong jenis tanaman sekunder, tanaman ini diminati masyarakat diberbagai kalangan. Masyarakat selain untuk menghijaukan pekarangan rumah, menambah estetika pekarangan juga untuk menaikan gengsi di masyarakat. Pada perkembangannya produksi tanaman hias diharapkan menjadi bisnis yang menjanjikan dikarenakan permintaannya yang setiap tahun semakin meningkat (Lakamisi, dkk. 2010).

Selain itu banyak negara saat ini sangat mendukung adanya ekspor bebagai jenis tanaman hias. Tanaman hias. Penentuan kebutuhan, keinginan dan minat pasar sasaran serta memberikan kepuasan konsumen dengan efektif dan efisien adalah tugas utama untuk tetap memelihara dan meningkatkan kesejahteraan masyarakat dan konsumen (Kotler, 2008). Pada saat memilih tanaman hias, konsumen akan melihat bagaimana bentuk tanamannya, warna tanaman, bunga serta kesegaran tanaman apakah sesuai dengan keinginan dari konsumen. Kebanyakan dari mereka membeli tanaman hias yang masih dalam polybag dan memindahkannya kedalam pot yang sesuai dengan keinginan konsumen. Konsumen sangat mempertimbangkan kemudahan dalam mendapatkan bibit (ketersediaan bibit) pada proses evaluasi alternatif dalam proses pengambilan keputusan (Nurjaya, 2018)

Pada tahun 2021 ini banyak negara-negara yg ada di dunia sedang mengalami dampak pandemi coronavirus. Indonesia menjadi salah satu negara dengan tingkat kasus covid19 yang cukup tinggi. Masyarakat Indonesia dihimbau untuk melakukan aktivitas dan kegiatan bekerja dirumah selama lebih dari 3 bulan. Hal ini 
mengakibatkan banyak masyarakat yang merasa bosan

Terbatasnya aktivitas diluar ruangan mendorong masyarakat untuk melakukan aktivitas dirumah seperti menanam tanaman hias. Tingginya permintaan tanaman hias disemua daerah sehingga mengakibatkan tingginya daya beli dan harga tanaman hias di setiap kabupaten/kota.

Kabupaten Lampung Utara termasuk kedalam 3 kabupaten dengan tingkat penyebaran Covid -19 yang tinggi di Provinsi Lampung (BAPPEDA Provinsi Lampung, 2021) sehingga banyak masyarakat melakukan aktivitas pekerjaan dan sekolah dirumah (daring). Sehubungan dengan hal tersebut maka semakin banyak warga masyarakat terutama ibu-ibu yang menghabiskan waktu mereka untuk merawat tanaman hias dirumah.

Produsen tanaman hias sudah seharusnya menyediakan produk tanaman yang berkualitas karena menurut Kotler (2008), menjelaskan konsumen bisa mendapatkan rangsangan dari luar yang terdiri dari bauran pemasaran, ekonomi, teknologi, politik, budaya sehingga dapat mempengaruhi pembelian dan menghasilkan tanggapan dari pembeli untuk melakukan keputusan pembelian.
Berdasarkan hal inilah maka produsen perlu melihat bagaimana kriteria tanaman hias yang diinginkan oleh konsumen sehingga produsen dapat menghasilkan produk yang diminati oleh konsumen.

Agar produsen dapat memahami perilaku konsumen, maka perlu dipahami jenis tanaman apa saja yang diminati serta faktor apa saja yang mempengaruhi keputusan konsumen untuk melakukan pembelian. Berdasarkan hal tersebut maka penelitian ini bertujuan untuk mengetahui jenis tanaman hias yang dibeli oleh konsumen di Kecamatan Kotabumi Selatan dan mengetahui faktor apa saja yang mempengaruhi keputusan konsumen untuk membeli tanaman hias di Kecamatan Kotabumi Selatan.

\section{METODE}

Penelitian ini menggunakan metode Survey (Singarimbun,1995). Penelitian ini difokuskan pada Kabupaten Lampung Utara karena kabupaten ini, termasuk kedalam 3 kabupaten dengan tingkat penyebaran Covid -19 yang tinggi di Provinsi Lampung (BAPPEDA Provinsi Lampung, 2021). Penelitian ini dilaksanakan di Kecamatan Kotabumi 
Selatan. Penentuan lokasi dilakukan secara sengaja (Purposive) (Suharsimi, 2002).

Metode accidental sampling atau sampel kebetulan digunakan untuk menetukan sampel. Pengambilan sampel menggunakan teknik cukup memberikan prasyarat yang ketat agar sampel yang dipilih sesuai dengan karakteristik yang dikehendaki dalam analisis (Juliandi, 2014). Sampel yang terpilih yaitu konsumen yang secara kebetulan bertemu pada saat turun lapang melakukan penelitian dan bersedia diwawancarai menggunakan kuisioner (Sugiyono, 2009).

Konsumen yang memiliki kriteria yang dapat dijadikan sampel dalam penelitian ini adalah (1) pernah melakukan pembelian minimal 1 kali dan ke (2) memiliki penghasilan. Sampel yang diperlukan dalam menggunakan analisis faktor adalah 4 atau 5 kali jumlah variabel (Malhotra, 2005). Variabel dalam penelitian ini berjumlah 4 sehingga responden nya berjumlah 20 responden.

Penelitian dilakukan dengan wawancara dan pengamatan langsung di lapangan. Teknik pengumpulan data primer diperoleh melalui pertanyaan yang telah disiapkan di Kecamatan Kotabumi Selatan. Kegiatan penelitian ini telah dilaksanakan pada bulan juli 2021.

\section{HASIL DAN PEMBAHASAN}

\section{a. Jenis Tanaman yang diminati}

Konsumen yang ingin membeli suatu produk memerlukan tanggapan atau keinginan serta harapan dalam keadaan yang diharapkan. Pada penelitian ini konsumen membeli tanaman hias dikarenakan adanya keinginan untuk melakukan aktivitas di dalam rumah sehingga tanaman hias dipilih untuk mengatasi keinginan tersebut. Jenis tanaman yang diminati oleh konsumen mulai dari berbagai Jenis Sri Rejeki (Aglaonema), Janda Bolong (Monstera Adansonii), Krisan, dan Bermacam Keladi. berdasarkan urutan peminat terbanyak adalah sri rejeki (Aglaonema).

Tanaman yang disukai oleh konsumen adalah tanaman yang memiliki berbagai macam warna dan variasi yang menarik. Selain warna dan adanya banyak variasi timbulnya tren baru di masyarakat meningkatkan pembelian tanaman hias. Untuk tanaman Sri Rejeki bisa di beli dengan harga berkisar Rp.20.000-200.000 tergantung dengan ukuran dan variasi tanaman Sri Rejeki. 
Pembelian suatu produk maka konsumen akan memilih untuk melakukan tahapan proses keputusan pembelian.

Menurut (Anita, dkk. 2014), tahapan proses pengambilan keputusan dimulai dengan tahap pengenalan kebutuhan, pencarian informasi, evaluasi alternatif, keputusan pembelian dan tahap evaluasi pasca pembelian. Meskupun hampir keseluruhan konsumen melalui proses pengambilan keputusan namun sebagian besar konsumen telah memiliki banyak informasi berdasarkan pengalaman yang dimiliki.

\section{b. Keputusan Pembelian Tanaman Hias Di Kecamatan Kotabumi Selatan}

$$
\text { Menurut Kotler (2000), }
$$

menyebutkan bahwa faktor utama yang mempengaruhi prilaku konsumen adalah faktor kebudayaan, faktor sosial faktor personal dan faktor psikologi. Hasil Penelitian mengenai keputusan pembelian Pembelian Tanaman Hias Selama Pandemi di Kecamatan Kotabumi Selatan, diperoleh dengan menggunakaan kuisioner yang berisi daftar pertanyaan kemudian diisi oleh 20 responden yang diberikan secara sengaja.
Menurut Malaihollo (2007), dalam penelitiannya menemukan bahwa faktor kebudayaan, sosial, pribadi dan psikologi juga berpengaruh terhadap keputusan pembelian. Dari penelitian diperoleh hasil bahwa berupa score nilai yang berasal dari faktor yang mempengaruhi keputusan pembelian yakni faktor budaya $\left(\mathrm{X}_{1}\right)$, faktor sosial $\left(\mathrm{X}_{2}\right)$, faktor pribadi $\left(\mathrm{X}_{3}\right)$ dan faktor psikologis $\left(\mathrm{X}_{4}\right)$.

Keseluruhan data yang dianalisis diketahui total nilai dan presentase dari masing-masing jenis faktor yang mempengaruhi keputusan pembelian (X) yaitu faktor kebudayaan $\left(\mathrm{X}_{1}\right)$ total 907 dengan 20,23 persen, faktor sosial $\left(\mathrm{X}_{2}\right)$ total 916 dengan 20,22 persen, faktor kepribadian $\left(\mathrm{X}_{3}\right)$ total 1604 dengan 35,41 persen, dan faktor psikologis $\left(\mathrm{X}_{4}\right)$ total 1103 dengan 24,35 persen. Presentase setiap faktor dapat dijelaskan dalam tabel sebagai berikut:

Tabel 1. Presentase setiap Faktor Pengambilan Keputusan Pembelian Tanaman Hias Tahun 2021

\begin{tabular}{llcc}
\hline No & Faktor & Total & Persentase \\
\hline 1 & Kebudayaan & 907 & 20,02 \\
& (X1) & & \\
2 & Sosial (X2) & 916 & 20,22 \\
3 & Kepribadian & 1604 & 35,41 \\
& (X3) & & \\
4 & Psikologis (X4) & 1103 & 24,35 \\
\hline \multicolumn{3}{c}{4530} & 100 \\
\hline \multicolumn{3}{c}{ Data Primer (olahan), 2021. }
\end{tabular}


Pada tabel 1 dapat dijelaskan bahwa faktor yang paling mempengaruhi adalah faktor kepribadian $\left(\mathrm{X}_{3}\right)$. Adanya keinginan pribadi dari konsumen untuk memiliki dan membeli tanaman hias sehingga mereka membeli produk tanaman hias untuk kebutuhan pribadi mereka misalnya mempercantik halaman rumah, melengkapi koleksi, dan sebagai pelepas bosan selama masa pandemi covid-19. Faktor kepribadian $\left(\mathrm{X}_{3}\right)$ memiliki total nilai yaitu sebesar 1604 dengan persentase 35,41 persen

Secara keseluruhan faktor budaya memperoleh total nilai sebesar 908 . Faktor kebudayaan diukur dengan menggunakan daftar pertanyaan yang berjumlah 6 butir dengan skor 1 sampai dengan 5. Diperoleh data bahwa faktor kebudayaan memiliki nilai maksimal sebesar 23,00 dengan nilai minimal sebesar 11,00 dan nilai rata-rata sebesar 18,18 .

Faktor sosial memperoleh total nilai sebesar 916. Seperti halnya faktor budaya, maka faktor sosial juga diukur dengan daftar pertanyaan yang berjumlah 6 butir dengan skor 1 sampai dengan 5. Data yang diperoleh bahwa nilai maksimal sebesar 22 sedangkan nilai minimal berjumlah 12 dengan nilai rata-rata sebesar 18,34.
Data yang diperoleh bahwa nilai maksimum yang diperoleh sebesar 28 dan nilai minimum sebesar 18 dengan rata-rata nilai sebesar 24,20.

Faktor psikologi dengan total nilai sebesar 1103. Diperoleh data bahwa nilai maksimum sebesar 26 dengan nilai minimum 17 dan nilai rata-rata sebesar 22 .

\section{PENUTUP}

\section{a. Simpulan}

Jenis tanaman hias yang banyak diminati konsumen mulai dari berbagai jenis sri rejeki (aglaonema), janda bolong (Monstera adansonii),krisan, dan bermacam keladi. berdasarkan urutan peminat terbanyak adalah sri rejeki (aglaonema).

Berdasarkan hasil analisis data didapatkan hasil yaitu Faktor yang mempengaruhi konsumen untuk membeli tanaman hias yakni yakni faktor budaya $\left(\mathrm{X}_{1}\right)$ sebesar 20,02 persen, faktor $\operatorname{sosial}\left(\mathrm{X}_{2}\right)$ sebesar 20,22 persen, faktor pribadi sebesar $\left(\mathrm{X}_{3}\right)$ 35,41 persen, dan faktor psikologis sebesar 24,35 persen sehingga faktor pribadi $\left(\mathrm{X}_{3}\right)$ sebesar 35,41 persen merupakan faktor terbesar yang mempengaruhi konsumen untuk melakukan pembelian tanaman hias. 
- Kesimpulan nya bahwa faktor pribadi $\left(\mathrm{X}_{3}\right)$ sebesar 35,41 persen dengan nilai total 1605 yang diperoleh dari penghitungan tabulasi angket penelitian merupakan faktor yang paling dominan mempengaruhi keputusan pembelian tanaman hias.

\section{b. Saran}

Adapun saran dalam penelitian ini adalah untuk meningkatkan proses penjualan tanaman hias para penjual diharapkan semakin meningkatkan produk sesuai dengan keinginan konsumen. Selain itu produsen juga harus berusaha memprediksi jenis tanaman apa yang akan diminati oleh konsumen dimasa yang akan datang.

\section{DAFTAR PUSTAKA}

BAPPEDA Provinsi Lampung. (2021).Data Covid-19 Provinsi Lampung Juli 2021 [internet] [diunduh 6 Juli 2021]. Tersedia pada

https://ppid.lampungprov.go.id/d etail-post/Data-Covid-19-

Provinsi-Lampung-Selasa-6-Juli2021.

Juliandi, A. Irfan M. (2014). Metodologi Penelitian Bisnis : Konsep dan Aplikasi. UMSU Press, Medan.
Kotler, P. (2008). Manajemen Pemasaran: Jilid 1 dan 2. Bumi Aksara, Jakarta.

Lakamisi, H. (2010). "Prospek Agribisnis Tanaman Hias Dalam Pot (Potplant)". Jurnal Ilmiah agribisnis dan Perikanan (agrikan UMMU-Ternate). Vol. 3(2) : 55-59.

Malaihollo, J. (2007) "Prilaku Konsumen Terhadap Keputusan Membeli Produk Air Minum Dalam Kemasan”. (Skripsi). Fakultas Ekonomi Universitas Kristen Indonesia. Jakarta.

Malhotra. (2005). Riset Pemasaran, Pendekatan Terapan: Edisi Keempat Jilid 2. Indeks Kelompok Gramedia, Jakarta.

Noviana, A., Yaktiworo,I.,Suryati,S. (2014). "Perilaku Konsumen Dalam Pembelian Tanaman Hias Di Kecamatan Pekalongan Kabupaten Lampung Timur". JIIA. VOLUME 2, No. 1: 77-85.

Nurjaya. (2018). “Kepuasan Konsumen Terhadap Penggunaan Bibit Tanaman Krisan

(Chrysanthemum sp.) Produk Balithi”. Agroscience. Vol 8 No.2 Tahun $2018: 160-179$

Singarimbun, M., \& Shofian E. (1995). Metode Penelitian Survey. LP3ES, Jakarta. 
Keputusan Konsumen Terhadap Pembelian Tanaman Hias Selama Pandemi di Kecamatan Kotabumi Selatan (Sari, dkk)

Suharsimi, A. (2002). Metodologi Sugiyono. (2009). Metode Penelitian Penelitian. Rineka Cipta, Jakarta.

Kuantitatif, Kualitatif dan $R$ \& D. Alfabeta, Bandung. 